Original article

\title{
The role of probiotics in combination therapy of depressive disorders
}

\author{
Sevilla R. Arifdjanova, Zera Z. Abrurakhmanova, Ekaterina S. Bizulya, Lesya N. Gumenyuk, Leya E. Sorokina, \\ Oksana Y. Gerbali
}

S.I. Georgievsky Medical Academy, V. I. Vernadsky Crimean Federal University, Simferopol, Russia

Received 9 November 2019, Revised 28 September 2020, Accepted 27 January 2021

C 2019, Arifdjanova S.R., Abrurakhmanova Z.Z., Bizulya E.S., Gumenyuk L.N., Sorokina L.E., Gerbali O.Y

(C) 2019, Russian Open Medical Journal

\begin{abstract}
Our objective was to investigate the effect of probiotic therapy on the profile of a psycho-emotional state and nature of neuroimmune-endocrine changes among patients with depressive disorders.

Material and methods - The study involved 119 patients, diagnosed with a mild depressive episode (F32.0) or a moderate depressive episode (F32.1). The patients were split among two groups: Main Group, in which subjects were taking a probiotic medicine in addition to the standard therapy (Cipralex + Bac-Set Forte), and Comparison Group in which subjects were taking a placebo pill in addition to the standard therapy (Cipralex). The Control Group consisted of 30 subjects belonging to the health group 1 sensu the Order of the Ministry of Health care of the Russian Federation No. 869an of January 1, 2018. The examination included clinical and psychopathological, psychometric, and laboratory methods.

Results - Patients with depressive disorders had dysfunction of cortisol and monoaminergic neurotransmitter systems, along with an increased content of proinflammatory cytokines and nitric oxide in their blood. As a result of the therapy with a probiotic medicine, in combination with an antidepressant, patients with depressive disorders had a statistically significant decrease in the levels of cortisol, dopamine, IL-6, TNF- $\alpha$, and NO, as well as a more pronounced reduction of depression symptoms, in comparison with the indicators of the patients who underwent standard therapy.

Conclusion - Use of probiotics resulted in a more pronounced improvement of neuro-immune-endocrine indicators in study subjects, with subsequent improvement of their mental state - particularly, due to less obvious symptoms of depressive disorders.
\end{abstract}

Keywords: depressive disorders, probiotics, antidepressant, neuro-immune-endocrine indicators.

Cite as Arifdjanova SR, Abrurakhmanova ZZ, Bizulya ES, Gumenyuk LN, Sorokina LE, Gerbali OY. The role of probiotics in combination therapy of depressive disorders. Russian Open Medical Journal 2021; 10: e0109.

Correspondence to Leya E. Sorokina. Address: 4 Academician Vernadsky St., Simferopol 295007, Republic of Crimea, Russia. E-mail: leya.sorokina@mail.ru.

\section{Introduction}

The issue of depressive disorders is among the most relevant in theory and practice of a modern psychiatry due to the fact that they are very widespread among the populations of top developed countries, and also because of a low effectiveness of their medical treatment [1].

Antidepressants remained the main pharmacological remedy for the therapy of depressive disorders since the 1980s. However, despite long-term clinical experience and a wide range of antidepressants currently used in psychiatry, $25-30 \%$ of patients are still lacking sufficiently acceptable results [2].

A promising research field constitutes studying the features of metabolic integration realized by means of the microbiota-gutbrain axis (gut-brain axis: GBA), which acts as a central link in neuro-immune-endocrine interactions [3-5]. Pathogenetic aspects of this communicative system functioning present a complicated issue, still insufficiently studied.

However, at present, many scientists worldwide agree that intestinal microflora disorders can play a key role in the development of depressive disorders [6-8]. The introduction of the full sequencing method that used the Illumina platform facilitated the identification of significant changes in the qualitative composition of intestinal microflora among patients with anxiety and depressive disorders. The results of some studies have shown that, in the chronic stress conditions, microbiota was mainly composed of Alistipes bacteria and that microbiota of patients with verified depression was dominated by Oscillobacter bacteria which produced valerianic acid. Valerianic acid competitively connects with gamma-aminobutyric acid (GABA) receptors, thus increasing an imbalance in the cerebrum GABAergic system [9].

As for molecular aspects of the microbiota-gut-brain axis functioning, endogenous lipopolysaccharide (LPS) plays an important role in the pathogenesis of this interaction. LPS is one of the major structural components of the gram-negative bacteria cell wall [10]. Dysbacteriosis leads to a decrease in intestinal permeability, which promotes interaction between LPS and TLR4 (Toll-like receptor 4) and activates signaling inflammatory processes that trigger nuclear transcription factors and intensive proinflammatory mediator production (tumor necrosis factor alpha - TNF- $\alpha$, interleukin-1 - IL-1, IL-6, interferon-alpha - IFN- $\alpha$ ), which leads to even greater severity of systemic inflammation [11- 
13]. It is well-known from some clinical studies that the introduction of IFN- $\alpha$ to treat patients with liver diseases caused the verified development of depression [14].

In 2004, N. Sudo and his co-authors [15] demonstrated that intestinal microbiota was the most important link in the formation of hypothalamic-pituitary-adrenal axis (HPAA). It is generally known that stress causes pathological activation of HPAA, which is followed by augmented production of adrenocorticotropic hormone, corticosterone, and cortisol. Disruption in their secretion is followed by changes in carbohydrate metabolism, which inhibits the immune response of the organism, and also affects mood, memory, and other cognitive functions [16, 17].

Additionally, intestinal bacteria per se are active producers of neurotransmitters (dopamine, noradrenaline, adrenaline, serotonin, GABA, etc.), which in turn directly affects brain activity and human behavior [18-21].

After interconnection between the state of intestinal microbiota and the development of various somatic pathologies was established, interest in a separate group of medicines probiotics - increased. Moreover, a few years ago, research findings of the group of Irish scientists from the National University of Ireland suggested that even a narrower group of medications - psychobiotics - could be defined within probiotics [22-26]. Thus, a particular interest is focused on the issue of the effectiveness in the use of probiotics as a potential (additional or alternative) vector of treating depressive disorders. Also, this vector is pathogenetically oriented.

Despite research results indicating that intestinal microbiome can be modified under the influence of probiotic medicines, with subsequent diminishing of depressive disorder symptoms, the quality of these (predominantly foreign) studies did not always meet the requirements of evidence-based medicine and, which dictates the necessity and relevance of further investigation of this issue.

Thus, the goal of our study was to investigate the probiotic therapy effect on the profile of the psycho-emotional state and nature of neuro-immune-endocrine changes among patients with depressive disorders.

\section{Material and Methods}

Our study involved 149 subjects 18 to 45 years old, 119 of which were conclusively diagnosed with a mild depressive episode (F32.0) or moderate depressive episode (F32.1), according to the classification criteria ICD-10, and had outpatient psychiatric treatment at various clinics in the city of Simferopol. Females constituted the majority of the sample $(74 ; 62.2 \%)$, while women were in minority $(45 ; 37.8 \%)$. The average age was $32.9 \pm 6.1$ years old.

The patients were accepted to participate in the study only if they complied with the following inclusion criteria: 1) females and males 18 to 45 years old; 2 ) mild depressive episode (F32.0) or moderate depressive episode $(F 32.1)$; 3$)$ primary depressive episode; 4) no symptoms of other mental disorders; 5) no concomitant chronic somatic and neurological diseases.

The exclusion criteria for the study were: 1) refusal to participate in the research at the initial stage; 2 ) severe depressive episode without psychotic symptoms (F32.2) and with psychotic symptoms (F32.3); 3) recurrent depressive disorder; 3) mental disorders of other diagnostic features (organic mental disorders, schizophrenia and other disorders of the schizophrenic spectrum, psychopathy, mental retardation); 3) pregnancy or lactation stage.

According to the design of a randomized placebo-controlled study, after being examined, the subjects with depressive disorders were randomly allocated to one of the following two groups: the Main Group $(n=60)$, in which patients were given a probiotic medicine in addition to the standard therapy; and the Comparison Group ( $n=59)$, in which patients were taking a placebo pill in addition to the standard treatment. The groups were compared in terms of major indicators of their demographic profile, and ailment duration and severity.

The Control Group comprised of 30 subjects 18 to 45 years old (the average age was $33.1 \pm 5.7$ years old) 30 subjects belonging to the health group 1 sensu the Order of the Ministry of Health care of the Russian Federation No. 869an of 01.01.2018.

Our research was conducted in accordance with the standards of Good Clinical Practice and the requirements of the World Medical Association Declaration of Helsinki. Our study was approved by the Ethics Committee of the S.I. Georgievsky Crimean Medical Academy of V.I. Vernadsky Crimean Federal University. Each participant had submitted a written informed consent before being included in the study. The examination was complex and comprehensive: it was based on clinical and psychopathological [27], psychometric, and laboratory methods. Within the framework of the psychometric study, Hamilton Depression Rating Scale (HDRS-17) (M. Hamilton, 1960) was used for obtaining the formalized statistical evaluation of the intensity and severity of depression symptoms [28]. The laboratory methods included three major techniques. Enzyme-linked immunosorbent assay (ELISA) was used to determine the content of cortisol and cytokines (IL-1 $\beta$, IL-6, TNF- $\alpha$ ) in blood serum (with test systems manufactured by Vector-Best JSC, Novosibirsk, Russia). The level of nitric oxide (NO) in blood plasma was determined with test systems by Systems (USA) and Biomedica Gruppe (Austria). High-performance liquid chromatography method (HPLC) was employed to identify the concentrations of noradrenaline and dopamine in blood plasma.

The patients with depressive disorders (two experimental groups) were examined on two occasions: when seeking help and after the 6-week therapy. The Control Group subjects were examined just once.

Standard antidepressant therapy was prescribed for no less than 90 days. All patients took an antidepressant Cipralex belonging to the group of selective serotonin reuptake inhibitors (manufactured by Lundbeck, Denmark, registration certificate of the Ministry of Healthcare of the Russian Federation No. 15653/01 of April 24, 2009). The medication was taken per os, at a single dose of $10 \mathrm{mg} /$ day, regardless of the meal. The probiotic correction was carried out with a multibiotic Bac-Set Forte (manufactured by Probiotics International Ltd., Lopen Head, South Petherton, Somerset, United Kingdom, registration certificate of the Ministry of Healthcare of the Russian Federation No. RU. 77.99.11.003.E.006375.12.16 of December 19, 2016). The multibiotic was also taken per os: 1 capsule 3 times a day during meals, for 6 weeks.

The software packages Statistica 10.0 and SPSS 23.0 were used for statistical data processing. WE tested collected data for normality, and their normal distribution was confirmed. Hence, we used the parametric statistical methods. For quantitative data, the arithmetic mean value (M), standard deviation, and standard error $( \pm m)$ were identified. The statistical significance of differences 
between the sample means was determined via the parametric Student's $t$-test. The differences were considered significant at $p<0.05$.

\section{Results}

The analyses of the content of biochemical blood markers in patients with depressive disorders before the treatment explicitly demonstrated the dysfunction of cortisol and monoaminergic neurotransmitter systems, along with increased levels of proinflammatory cytokines and nitric oxide.

Before the therapy, the level of cortisol in the blood of patients with depressive disorders significantly exceeded the values for the patients in the Control Group: it was 1.9 times higher $(p<0.001)$. After the treatment, the groups had a statistically significant cortisol decline below the baseline level: these changes were more profound in the Main Group (cortisol concentration there was 1.2 times lower than in the Comparison Group, $p=0.032$ ), while the values of the indicators were very close to those in the Control Group.

Average levels of noradrenaline and dopamine in blood serum of the patients with depressive disorders before the treatment were significantly higher, compared with the results of the Control Group: 3.4 times higher $(p<0.001)$ and 2.1 times higher $(p<0.001)$, respectively. This finding implied the clear role of catecholamines in pathogenesis of depressive disorders. After the therapy, the noradrenaline levels dropped down below the baseline in both experimental groups; however, the indicators in the Main Group and Comparison Group were not statistically different from each other, and they exceeded the values of the Control Group. In the course of our study, it has become obvious that dopamine content was decreasing with treatment, but changes in the Main Group were more profound compared with the indicators in the Comparison Group: they were 1.5 times higher $(p=0.008)$, becoming very close to those in the Control Group. The dynamics of cortisol content and the levels of biogenic amines during the therapy are presented in Table 1.

The average background levels (i.e., before the treatment) of studied proinflammatory cytokines in the blood of patients with depressive disorders significantly exceeded the values in the Control Group, with the highest recorded values of the IL-6 indicator being 3.7 times higher $(p<0.001)$, which confirmed the priority indicative value of this cytokine association with depression. During the therapy, the experimental groups had similar dynamics of changes of the entire investigated cytokine profile: IL-1 $\beta$ values were characterized by the inertness of changes and did not show any statistically significant pattern; the levels of IL- 6 and TNF- $\alpha$ decreased significantly, but their dynamics in the Main Group was more pronounced compared with the Comparison Group: their values after the therapy were 1.6 times higher $(p=0.002)$ and 1.4 times higher $(p=0.032)$, respectively, in the Comparison Group (Table 2).

Before the therapy, the average nitric oxide (NO) level (II) in patients suffering from depressive disorders was significantly higher (2.7 and 2.6 times, respectively, for Main Group and Comparison Group) in comparison with the Control Group, which proved the importance of $\mathrm{NO}$ as a control marker of stress response by the neuro-immune-endocrine system. After six weeks of therapy, patients with depressive disorders had statistically significantly declined NO values compared to the baseline, and before-and-after changes were 1.4 times greater in the Main
Group compared with the Comparison Group ( $p=0.049)$; however, after-therapy values in both groups did not approach the level of the Control Group (Table 3).

The effectiveness of treating the patients with depressive disorders, who were taking a probiotic medicine in addition to the standard therapy, was confirmed by the results of dynamic monitoring based on the HDRS-17 scale. Before the treatment, the degree of depression degree in the Main Group was 12.4 \pm 4.6 ; whereas in the Comparison Group, it was $11.9 \pm 4.9$ points. After the 6-week therapy, according to the reduction index of the average total score, 50 patients (84.1\%) and 41 patients (69.9\%) $(p=0.083)$ from each group, respectively, experienced a therapeutic effect which was classified as 'significant'; 12 patients (20.2\%) and 16 patients (26.3\%), respectively, experienced a 'moderate' therapeutic effect. At the same time, the average total score according to the HDRS-17 scale declined by at least $56 \%$ in the Main Group, and by $44 \%$ in the Comparison Group.

\section{Discussion}

The study of the effectiveness of using probiotics as additional remedies in pathogenetically justified treatment of depressive disorders showed their positive impact.

Our research results revealed a more pronounced positive trend to normalized concentrations of glucocorticoids, catecholamines, proinflammatory cytokines, and nitric oxide in the patients undergoing the combination therapy (antidepressant + probiotic) compared with the patients receiving antidepressantand-placebo therapy, which is consistent with the results of studies carried out by other authors, in which they have proved the positive effect of probiotics on normalization of neuroimmune-endocrine status in mental disorders.

Thus, before the treatment, the concentration of cortisol in patients with depressive disorders significantly exceeded the corresponding values in the Control Group, which is typical for primary episodes of depression and is consistent with the concept of allostatic load. The latter has been recently widely discussed in foreign biological psychiatry.

Keeping in mind the fact that elevated cortisol content is considered a physiological biomarker of emotional disorders, its statistically significant decline in Main Group subjects, observed in our study, may be regarded a proof of severity reduction in depressive disorders. Our results confirmed the published data, which demonstrated that decrease in cortisol level have resulted in less pronounced depression symptoms, both directly in the structure of a depressive episode and within the framework of schizophrenia.

It is generally known that dopamine, adrenaline, and noradrenaline, which belong to the group of catecholamines, are synthesized from L-tyrosine in various parts of the brain, in adrenal glands, and in some sympathetic nerve fibers. At the same time, adrenaline and noradrenaline are main neurotransmitters responsible for the development of a stress response. Along with cortisol, these hormones activate HPAA, which causes hyperactivity of the sympathetic nervous system. The latter is a key pathogenetic link in the development of depression and anxiety. Also, adrenaline and noradrenaline affect intestinal microflora by contributing to the growth and virulence of anaerobic bacteria Bacteroides and other opportunistic populations, which leads to an increase in the local production of catecholamines and, in turn, closes the vicious circle. 
Table 1. Dynamics of cortisol and biogenic amines content in blood of patients with depressive disorders during the therapy

\begin{tabular}{lcccc}
\hline Indicators & $\begin{array}{c}\text { Control Group } \\
(n=30)\end{array}$ & $\begin{array}{c}\text { Main Group before } \\
\text { the therapy }(n=60)\end{array}$ & $\begin{array}{c}\text { Comparison Group before } \\
\text { the therapy }(n=59)\end{array}$ & $\begin{array}{c}\text { Main Group after the } \\
\text { therapy }(n=60)\end{array}$ \\
\hline Cortisol, $\mathrm{nmol} / \mathrm{l}$ & $353.5 \pm 102.1$ & $751.5 \pm 112.6 * * *$ & $754.5 \pm 114.5^{* * *}$ & $389.4 \pm 37.5 \bullet \bullet \bullet$ \\
Noradrenaline, $\mathrm{pg} / \mathrm{ml}$ & $139.2 \pm 39.2$ & $473.9 \pm 154.2 * * *$ & $476.2 \pm 151.3^{* * *}$ & $463.4 \pm 28.3 * \bullet \bullet$ \\
Dopamine, $\mathrm{pg} / \mathrm{ml}$ & $27.3 \pm 5.7$ & $58.7 \pm 12.7 * *$ & $56.9 \pm 11.9 * *$ & $38.8 \pm 87.1 * *$ \\
\hline
\end{tabular}

** $\mathrm{p}<0.01$ compared with the Control Group; ${ }^{* * *} \mathrm{p}<0.001$ compared with the Control Group; $\bullet p<0.05$ compared to the baseline; $\bullet \bullet<0.01$ compared to the baseline; $\bullet \bullet p<0.001$ compared to the baseline; \# $<<0.05$ compared with the indicators in the Main Group and Comparison Group; \#\# $<<0.01$ compared with the indicators in the Main Group and Comparison Group.

Table 2. Dynamics of proinflammatory cytokines in blood of patients with depressive disorders during the therapy

\begin{tabular}{|c|c|c|c|c|c|}
\hline Indicators & $\begin{array}{c}\text { Control Group } \\
(n=30)\end{array}$ & $\begin{array}{c}\text { Main Group before the } \\
\text { therapy }(n=60)\end{array}$ & $\begin{array}{c}\text { Comparison Group before } \\
\text { the therapy }(n=59)\end{array}$ & $\begin{array}{l}\text { Main Group after } \\
\text { the therapy }(n=60)\end{array}$ & $\begin{array}{c}\text { Comparison Group after } \\
\text { the therapy }(n=60)\end{array}$ \\
\hline $\mathrm{IL}-1 \beta, \mathrm{pg} / \mathrm{ml}$ & $3.7 \pm 1.0$ & $6.4 \pm 0.8^{*}$ & $6.4 \pm 0.7^{*}$ & $5.9 \pm 0.5$ & $5.8 \pm 0.6$ \\
\hline IL-6, pg/ml & $3.8 \pm 0.8$ & $14.1 \pm 0.9 * * *$ & $13.9 \pm 0.9 * * *$ & $4.9 \pm 0.7 \bullet \bullet \bullet$ & $7.9 \pm 0.9 * * \bullet \bullet \# \#$ \\
\hline TNF- $\alpha, p g / m l$ & $2.2 \pm 0.2$ & $7.3 \pm 0.3 * *$ & $7.6 \pm 0.2 * *$ & $4.3 \pm 0.3 * \bullet \bullet$ & $6.1 \pm 0.3 * * \bullet \bullet \bullet \#$ \\
\hline
\end{tabular}

** $\mathrm{p}<0.01$ compared with the Control Group; *** $\mathrm{p}<0.001$ compared with the Control Group; $\bullet p<0.05$ compared to the baseline; $\bullet \bullet<0.01$ compared to the baseline; $\cdots p<0.001$ compared to the baseline; \# $p<0.05$ compared with the indicators in the Main Group and Comparison Group; \#\# $p<0.01$ compared with the indicators in the Main Group and Comparison Group.

Table 3. Dynamics of nitric oxide (II) content in blood of patients with depressive disorders during the therapy

\begin{tabular}{lcccc}
\hline Indicators & $\begin{array}{c}\text { Control Group } \\
(n=30)\end{array}$ & $\begin{array}{c}\text { Main Group before the } \\
\text { therapy }(n=60)\end{array}$ & $\begin{array}{c}\text { Comparison Group before } \\
\text { the therapy }(n=59)\end{array}$ & $\begin{array}{c}\text { Main Group after } \\
\text { the therapy }(n=60)\end{array}$ \\
\hline $\mathrm{NO}, \mathrm{mcmol} / \mathrm{l}$ & $3.7 \pm 4.2$ & $9.9 \pm 0.5^{* * *}$ & $9.8 \pm 0.6^{* * *}$ & $\begin{array}{c}\text { Comparison Group after } \\
\text { the therapy }(n=60)\end{array}$ \\
\hline
\end{tabular}

** $p<0.01$ compared with the Control Group; *** $\mathrm{p}<0.001$ compared with the Control Group; $\bullet p<0.05$ compared to the baseline; $\bullet p<0.01$ compared to the baseline; \# $p<0.05$ compared with the indicators in the Main Group and Comparison Group.

Dopamine often causes its physiological effects through the neurotransmission system called the internal reinforcement system, which is responsible for positive mood as a reward for achieving certain results.

The results of our research (general tendency to normalize the concentration of biogenic amines among patients in the Main Group after a therapy) showed that the use of probiotics against the background of depressive disorders reduced the HPAA activity. Therefore, the use of a probiotic medication in combination with an antidepressant provided a more pronounced corrective effect on limiting stress response. The obtained data were consistent with the results of previous studies. In particular, an experimental study, performed by A.I. Ugolev, showed that animals, raised in sterile conditions and therefore deprived of microbiota, responded to stress with varying degrees of inadequacy, compared with the control group. This finding implied that the intestinal microbiome was a causal factor in the HPAA formation [1, 2-5].

It is believed that the phenomenon of dysbiosis is followed by increased intestinal permeability when bacteria penetrate into the bloodstream. As soon as these bacteria die, endotoxin of lipopolysaccharide nature is released, triggering the formation of immunological and inflammatory response with an increase in the levels of systemic proinflammatory cytokines. Our study has also provided the evidence of possible immunological effects of probiotics. In particular, after the therapy, the IL-1 $\beta$ values were characterized by an inertness of changes and did not exhibit statistical significance, whereas the content of IL- 6 and TNF- $\alpha$ declined reliably. At the same time, dynamics in the Main Group versus Comparison Group was more pronounced. Since IL- 6 is generally considered a marker of the positive response to therapy, special attention should be paid to our finding that there were no significant differences in the values of this cytokine between the Main Group and the Control Group, which has confirmed a more pronounced immunotropic effect of a probiotic medication in combination with an antidepressant and indicated a decrease in the severity of systemic inflammation. The observed trend was consistent with experimental and clinical data of other researchers $[19,23]$.

Although the depression mechanism is still a complicated and disputable issue, it is, however, reliably known that stress, inflammation, and endogenous intoxication are the triggers initiating this disorder. These factors may influence the functional activity of glutamate $\mathrm{N}$-methyl-D-aspartate (NMDA) receptors in neuronal membranes, which would result in a systemic disturbance of excitatory glutamatergic transmission in the brain. Moreover, activation of non-synaptic NMDA receptors leads to accumulation of $\mathrm{Ca}^{2+}$ in neuroplasm, which could induce an augmented activity of neuronal nitric oxide (NO) synthase causing degenerative and atrophic damage to neurons. In turn, as a result of these processes, cognitive and emotional responses of the brain are impaired. In the course of our study, after the six-week therapy, patients with depressive disorders had a statistically significant decrease in NO content compared to the baseline, especially in the group taking a probiotic in combination with an antidepressant. While analyzing the published sources, we did not find any studies investigating the effect of a probiotic on the NO level in depressive disorders. However, several publications presented some evidence on the role of probiotics in correcting endothelial dysfunction and preventing postoperative complications [29].

Besides, the effectiveness of the therapy in patients with depressive disorders taking a probiotic medication in addition to the standard therapy was confirmed by the results of dynamic monitoring based on the HDRS-17 scale. Similar results were collected in the course of a controlled randomized study on the dependence of mood on probiotic intake: after taking a probiotic mixture during four weeks, study participants (healthy males and females) exhibited a significantly less pronounced response to 
inducers of bad mood in comparison with the placebo group, which was established by computing the values of the Depression Sensitivity Scale index.

Thus, the substantiated use of probiotics opens up prospects of a novel pathogenesis-based approach to a complex therapy of depressive and anxiety disorders.

\section{Conclusions}

1. Patients with depressive disorders had dysfunction of cortisol and monoaminergic neurotransmitter systems, along with increased levels of proinflammatory cytokines and nitric oxide in their blood. As a result of complex therapy that combined the use of a probiotic medication and an antidepressant, there was a more pronounced statistically significant decrease in dopamine concentration in comparison with the standard treatment.

2. The introduction of combination therapy with the use of a probiotic pill and an antidepressant could significantly reduce blood content of cortisol, dopamine, some proinflammatory cytokines (in particular, IL-6 and TNF- $\alpha$ ) and nitric oxide, which promoted the reduction of manifestation severity of clinical depressive disorders.

3. The results of our study implied the possibility of intestinal microbiome modification under the influence of probiotics, with further improvement of mental state, in particular, by reducing the symptoms of depressive disorders. Hence, our results confirmed the necessity to include probiotics in the scheme of the combination therapy for this category of patients as a pathogenetically justified treatment method.

\section{Conflict of interest}

We declare that we have no conflict of interest.

\section{References}

1. Bacherikov AN, Denysenko MM. Clinical-psychopathological, pathopsychological peculiarities and principles for prevention of a suicidal behavior in patients with endogenous and exogenous depressions. Ukrains'kyi Visnyk Psykhonevrolohii 2010; 18(4(65)): 5660. Russian. https://www.elibrary.ru/item.asp?id=20138276.

2. Kozhyna AM, Korostiy VI, Zelenskaia EA, Khmain S. Psychogenic depressions and suicide behavior in young people. Medical Psychology 2013; 8(4):42-45. Russian. http://www.irbis-nbuv.gov.ua/cgibin/irbis nbuv/cgiirbis 64.exe?C21COM=2\&/21DBN=UJRN\&P21DBN= UJRN\&Z21ID=\&IMAGE_FILE_DOWNLOAD=1\&Image_file_name=PDF/ Mpsl 2013 8 4 13.pdf.

3. Ryabichenko EV, Bondarenko VM. Gut-brain interrelationships in health and disease. Upper Volga Medical Journal 2013; 11(1): 34-39. Russian. https://www.elibrary.ru/item.asp?id=18954518.

4. Mayer EA. Gut feelings: The emerging biology of gut-brain communication. Nat Rev Neurosci 2011; 12(8): 453-466. https://doi.org/10.1038/nrn3071.

5. Bondarenko VM, Ryabichenko EV. Pathogenetic mechanisms and principle therapy of diseases with impaired gut-brain axis. Bjulleten' Orenburgskogo nauchnogo centra UrO RAN 2013; (4): 1-15. Russian. https://www.elibrary.ru/item.asp?id=21123945.

6. Asano $Y$, Hiramoto $T$, Nishino R, Aiba $Y$, Kimura $T$, Yoshihara $K$, et al. Critical role of gut microbiota in the production of biologically active, free catecholamines in the gut lumen of mice. Am J Physiol Gastrointest Liver Physiol 2012; 303(11): G1288-G1295. https://doi.org/10.1152/ajpgi.00341.2012.
7. Norris V, Molina F, Gewirtz AT. Hypothesis: Bacteria control host appetites. J Bacteriol 2013; 195(3): 411-416. https://doi.org/10.1128/ib.01384-12.

8. Oleskin AV, Shishov VI, Malikina KD. Symbiotic biofilms and brain neurochemistry. Hauppauge, N.Y., United States: Nova Science Publishers, 2010; 65 p. https://trove.nla.gov.au/work/37672052.

9. Naseribafrouei A, Hestad K, Avershina E, Sekelja M, Linløkken A, Wilson $\mathrm{R}$, et al. Correlation between the human fecal microbiota and depression. Neurogastroenterol Motil 2014; 26(8): 1155-1162. https://doi.org/10.1111/nmo.12378.

10. Qin L, Wu X, Block ML, Liu Y, Breese GR, Hong JS, et al. Systemic LPS causes chronic neuroinflammation and progressive neurodegeneration. Glia 2007; 55(5): 453-462. https://doi.org/10.1002/glia.20467.

11. Wasilewski A, Zielińska M, Storr M, Fichna J. Beneficial Effects of Probiotics, Prebiotics, Synbiotics, and Psychobiotics in Inflammatory Bowel Disease. Inflamm Bowel Dis 2015; 21(7): 1674-1682. https://doi.org/10.1097/mib.0000000000000364.

12. Desbonnet L, Garrett L, Clarke G, Bienenstock J, Dinan TG. The probiotic Bidobacteria infantis: An assessment of potential antidepressant properties in the rat. J Psychiatr Res 2008; 43(2): 164174. https://doi.org/10.1016/j.jpsychires.2008.03.009.

13. Shilov luE, Bezrukov MV. Kynurenines in pathogenesis of endogenous psychiatric disorders. Vestn Ross Akad Med Nauk 2013; (1): 35-41. Russian. https://doi.org/10.15690/vramn.v68i1.535.

14. Udina $M$, Castellví $P$, Moreno-España J, Navinés $R$, Valdés $M$, Forns $X$, et al. Interferon-induced depression in chronic hepatitis C: a systematic review and meta-analysis. J Clin Psychiatry 2012; 73(8): 1128-1238. https://doi.org/10.4088/icp.12r07694.

15. Sudo N, Chida Y, Aiba Y, Sonoda J, Oyama N, Yu XN, et al. Postnatal microbial colonization programs the hypothalamic-pituitary-adrenal system for stress response in mice. J Physiol 2004; 558(Pt 1): 263-275. https://doi.org/10.1113/iphysiol.2004.063388.

16. Bhagwagar

?]zfterafizi? S, Cow waking in depression. Psychopharmacology (Berl) 2005; 182(1): 54-57. https://doi.org/10.1007/s00213-005-0062-z.

17. Mannie

levels in young people at familial risk of depression. Am J Psychiatry 2007; 164(4): 617-621. https://doi.org/10.1176/ajp.2007.164.4.617.

18. Asano $Y$, Hiramoto $T$, Nishino R, Aiba $Y$, Kimura $T$, Yoshihara $K$, et al. Critical role of gut microbiota in the production of biologically active, free catecholamines in the gut lumen of mice. Am J Physiol Gastrointest Liver Physiol 2012; 303(11): G1288-G1295. https://doi.org/10.1152/ajpgi.00341.2012.

19. Berridge $\mathrm{KC}$, Robinson TE. What is the role of dopamine in reward: Hedonic impact, reward learning or incentive salience? Brain Res Brain Res Rev 1998; 28(3): 309-369. https://doi.org/10.1016/s01650173(98)00019-8.

20. Clarke G, Stilling RM, Kennedy PJ, Stanton C, Cryan JF, Dinan TG. Minireview: Gut microbiota: the neglected endocrine organ. Mol Endocrinol 2014; 28(8): 1221-1238. https://doi.org/10.1210/me.2014$\underline{1108 .}$.

21. Hwang CC, Lee YC, Huang YR, Lin CM, Shian CY, Hwang DF, et al. Biogenic amines content, histamine-forming bacteria and adulteration of bonito in tuna candy products. Food Control 2010; 21(6): 845-850. http://doi.org/10.1016/j.foodcont.2009.11.011.

22. Medinets S, Skiba U, Rennenberg H, Butterbach-Bahl K. A review of soil NO transformation: Associated processes and possible physiological significance on organisms. Soil Biology and Biochemistry 2015; 80: $92-$ 117. https://doi.org/10.1016/j.soilbio.2014.09.025.

23. Dinan TG, Stanton C, Cryan JF. Psychobiotics: a novel class of psychotropic. Biol Psychiatry 2013; 74(10): 720-726. https://doi.org/10.1016/j.biopsych.2013.05.001.

24. Messaoudi 
(Lactobacillus helveticus R0052 and Bifidobacterium longum R0175) in rats and human subjects. Br J Nutr 2011; 105(5): 755-764. https://doi.org/10.1017/s0007114510004319.

25. Bravo

Dinan

behavior and central GABA receptor expression in a mouse via the vagus nerve. Proc Natl Acad Sci U S A 2011; 108(38): 16050-16055. https://doi.org/10.1073/pnas.1102999108.

26. Yang H. Zhao X. Tang S. Huang H. Zhao X, Ning Z, et al. Probiotics reduce psychological stress in patients before laryngeal cancer surgery. Asia Pac J Clin Oncol 2016; 12(1): e92-e96. https://doi.org/10.1111/ajco.12120.

27. Gelder M, Gath D, Mayou R, Cowen P. Oxford Textbook of Psychiatry. 3rd ed. Oxford: Oxford Medical Publications. 1996; 944 p.

28. Tarabrina NV. Workshop on the psychology of post-traumatic stress. St. Petersburg, Russia: Peter, 2001. 268 p. Russian.

29. Privolnev V.V. Prospects for the use of probiotics to reduce postoperative complications. Bulletin of the Smolensk State Medical Academy. 2016; $15 \quad$ (4): 142-149. Russian. https://elibrary.ru/item.asp?id=28299507.

Authors:

Sevilla R. Arifdjanova - Senior year (Year 6) student, S.I. Georgievsky Medical Academy, V.I. Vernadsky Crimean Federal University, Simferopol, Russia. https://orcid.org/0000-0002-9091-4097.

Zera Z. Abrurakhmanova - Senior year (Year 6) student, S.I. Georgievsky Medical Academy, V.I. Vernadsky Crimean Federal University, Simferopol, Russia. https://orcid.org/0000-0001-7977-4196.

Ekaterina S. Bizulya - Senior year (Year 6) student, S.I. Georgievsky Medical Academy, V.I. Vernadsky Crimean Federal University, Simferopol, Russia. https://orcid.org/0000-0003-0488-3771.

Lesya N. Gumenyuk - MD, DSc, Professor, School of Training Medical Personnel of the Highest Qualification and Supplementary Vocational Education, Department of Psychiatry, Narcology, Psychotherapy with the Course of General and Medical Psychology, S.I. Georgievsky Medical Academy, V.I. Vernadsky Crimean Federal University, Simferopol, Russia. http://orcid.org/0000-0003-2785-3882.

Leya E. Sorokina - Senior year (Year 5) student, S.I. Georgievsky Medical Academy, V.I. Vernadsky Crimean Federal University, Simferopol, Russia. https://orcid.org/0000-0002-1862-6816.

Oksana Y. Gerbali - MD, Associate Professor, School of Medicine, Department of Surgery No. 1, S.I. Georgievsky Medical Academy, V.I. Vernadsky Crimean Federal University, Simferopol, Russia. https://orcid.org/0000-0001-7601-6226.
?JA, Forsythe?P, Chew?MV, Escaravage? $\mathrm{E}$, Savignac? $\mathrm{HM}$, ?TG, et al. Ingestion of Lactobacillus strain regulates emotiona 